\title{
A INSERÇÃO DA EQUIPE DE SAÚDE DA FAMÍLIA NO AMBIENTE ESCOLAR PÚBLICO: PERSPECTIVA DO PROFESSOR
}

\author{
Sirlei Cristina Godoi ${ }^{1}$, Pâmela de Pol $^{2}$, Graciele de Matia ${ }^{3}$
}

\begin{abstract}
RESUMO: Estudo de abordagem qualitativa e de tipo exploratório-descritivo teve por objetivo investigar a percepção do professor sobre a inserção da equipe de Saúde da Família, apontando suas necessidades de informação. O estudo foi desenvolvido em 2010 com 12 participantes em 9 escolas estaduais de Curitiba-PR, utilizou-se para coleta de dados entrevista semiestruturada. Da análise de conteúdo emergiram quatro categorias: Interação entre profissionais de educação e profissionais de saúde; Inserção de profissionais de saúde na escola; Cuidados e informações aos alunos-adolescentes; e Desafios dos profissionais de educação ao trabalhar com alunos-adolescentes. Os temas indicados para abordagem foram violência, drogadição, doenças sexualmente transmissíveis, higiene, alimentação e autoestima. Os resultados indicaram a oportunidade de desenvolvimento de trabalho multidisciplinar no ambiente escolar e que a integração entre Escola e Estratégia da Saúde da Família é mandatória para o desenvolvimento de ações de prevenção e promoção à saúde junto aos escolares. PALAVRAS-CHAVE: Saúde dos adolescentes; Prevenção primária; Saúde da família; Enfermagem.

\section{THE INSERTION OF THE FAMILY HEALTHCARE TEAM IN A STATE SCHOOL ENVIRONMENT: A TEACHER'S PERSPECTIVE}

ABSTRACT: This exploratory-descriptive study with a qualitative approach aimed to investigate how teachers perceive the insertion of the Family Healthcare team, pinpointing their need for information. The study was developed in 2010 with 12 participants in 9 state schools in Curitiba in the state of Paraná, and used semi-structured interviews for collecting data. Four categories emerged from content analysis: Interaction between education professionals and health professionals; Insertion of healthcare professionals in schools; Care and information for adolescent students; and Challenges for education professionals in working with adolescent students. The themes indicated for approach were violence, drug addiction, sexually transmitted diseases, hygiene, nutrition and self-esteem. The results included the opportunity for the development of multidisciplinary work in the school environment and that integration of the school with the Family Health Strategy is mandatory for the development of actions for prevention and health promotion in company with the students.

KEYWORDS: Adolescent health; Primary prevention; Family health; Nursing.

\section{LA INSERCIÓN DEL EQUIPO DE SALUD DE LA FAMILIA EN EL AMBIENTE ESCOLAR PÚBLICO: PERSPECTIVA DEL PROFESOR}

RESUMEN: Estudio de abordaje cualitativo y de tipo exploratorio y descriptivo cuyo objetivo fue investigar la percepción del profesor acerca de la inserción del equipo de Salud de la Familia, indicando sus necesidades de información. El estudio fue desarrollado en 2010 con 12 participantes en 9 escuelas estaduales de Curitiba-PR; fue utilizada para recoger los datos entrevista semi estructurada. Del análisis de contenido surgieron cuatro categorías: Interacción entre profesionales de educación y profesionales de salud; Inserción de profesionales de salud en la escuela; Cuidados e informaciones a los alumnos adolescentes; y Desafíos de los profesionales de educación al trabajar con alumnos adolescentes. Los temas indicados para abordaje fueron violencia, drogadicción, enfermedades sexualmente transmisibles, higiene, alimentación y autoestima. Los resultados indicaron la oportunidad de desarrollo de trabajo multidisciplinar en el ambiente escolar y que la integración entre Escuela y estrategia de la Salud de la Familia es esencial para el desarrollo de acciones de prevención y promoción a la salud junto a los estudiantes. PALABRAS CLAVE: Salud de los adolescentes; Prevención primaria; Salud de la Familia; Enfermería.

\footnotetext{
${ }^{1}$ Enfermeira. Auxiliar de consultório odontológico da Secretaria Municipal de Saúde de Curitiba-PR.

${ }^{2}$ Enfermeira do Hospital Pequeno Príncipe.

${ }^{3}$ Enfermeira. Especialista em Administração Hospitalar e Clínicas, Formação Pedagógica para Profissionais da Área da Saúde e Metodologias Ativas. Professora da Faculdades Pequeno Príncipe - Curitiba-PR
}

Autor correspondente:

Graciele de Matia

Faculdades Pequeno Príncipe

Rua Uberlândia, 339 - 82220-260 - Curitiba-PR-Brasil

E-mail: graciele.matia@ig.com.br
Recebido: 24/08/2011 Aprovado: 13/04/2012 


\section{INTRODUÇÃO}

A temática saúde adentrou as escolas brasileiras durante o final do século XIX. À época considerava-se tanto a dimensão assistencial quanto atitudinal, em que se priorizava o desenvolvimento de hábitos, atitudes e valores de acordo com a concepção de indivíduo saudável dominante no período. Ou seja, constituíase um conjunto de normas com a finalidade de evitar que doenças infecto-contagiosas fossem transmitidas na escola ${ }^{(1)}$. Desde então, muitas discussões em torno das relações entre educação e saúde são conduzidas; na atualidade, tais preocupações reúnem-se numa instância denominada saúde escolar. A Portaria Interministerial n. 766/GM de 17 de maio de 2001 normatiza a elaboração dos Parâmetros Curriculares Nacionais em Ação e estabelece o pacto entre o Ministério da Saúde e o Mistério da Educação( ${ }^{(2)}$.

As escolas de ensino fundamental e médio têm como meta o desenvolvimento de habilidades individuais e sociais que auxiliem crianças e adolescentes na construção de suas vidas e na contribuição para a vida de outros com os quais se relacionam. Como instituições sociais, as escolas devem ser ambientes de convívio onde a interação pessoal, criativa e autônoma direcione para a educação, a ação, a participação e a autoajuda através da consciência crítica e ampliação da liberdade ${ }^{(3)}$.

As crianças e os adolescentes, principalmente, vivenciam um período de vida constituído por transformações, dúvidas e inúmeras interrogações, uma fase de novas descobertas e a busca da autonomia, sendo esta parte do processo na formação do jovem ${ }^{(4)}$. Um método possível para a atuação da equipe de saúde da família aponta para a educação permanente em saúde nas escolas, buscando discutir e analisar temáticas relacionadas à realidade vivenciada pelos estudantes, a fim de favorecer seu crescimento e possibilitar mudanças, centralizando a educação como fonte propulsora de transformação $0^{(5)}$.

As escolas têm sido consideradas espaços sociais adequados para a promoção da saúde de crianças e adolescentes uma vez que podem, com eficácia, promover sua saúde, autoestima, formação de comportamentos, além de habilidades para a vida cotidiana, tais como: capacidade para tomadas de decisão, comunicação, compreensão de emoções, pensamento crítico e manejo de estresse. As escolas podem caracterizar-se por um espaço onde a saúde de todos os membros da comunidade, sejam professores, funcionários e familiares, e dos próprios estudantes, pode ser promovida ${ }^{(6)}$.
A abordagem da temática educação para a saúde oferece espaço para a atuação da equipe de saúde da família, inclusive em escolas através da realização de práticas educativas com escolares ${ }^{(7)}$. A educação para a saúde pode, então, constituir-se em instrumento de empoderamento do enfermeiro ao propiciar o alargamento do cuidado à saúde do escolar ${ }^{(8)}$.

Comprovadamente a equipe de saúde da família pode e deve atuar por meio de atividades de educação para a saúde e de práticas educativas, em diferentes espaços, mas principalmente nas escolas ${ }^{(7)}$. Tem-se, portanto, um processo que visa à promoção de saúde de escolares. Neste sentido, a equipe de saúde da família pode atuar como educador para a saúde, trabalhando no intuito de preparar o indivíduo para o autocuidado, e facilitador nas tomadas de decisões desse sujeito ${ }^{(9)}$.

Desde 1995 o Ministério da Saúde e o Ministério da Educação do Brasil têm, conjuntamente, reunido esforços para que os temas em saúde sexual e saúde reprodutiva sejam trabalhados nas escolas pelo Programa Saúde e Prevenção nas Escolas.

Em 2005 o programa "Saúde e Prevenção nas Escolas" foi reformulado, novas estratégias foram definidas, entre elas, o monitoramento das escolas a partir da inclusão de um questionário específico no Censo Escolar; a incorporação de diretrizes para que as ações possam atingir alunos a partir das primeiras séries do ensino fundamental; o apoio a estados e municípios na constituição de 22 grupos gestores intersetoriais nas 27 Unidades Federais; a realização de oficinas macrorregionais; o apoio a eventos regionais e a produção, impressão e distribuição de materiais educativos ${ }^{(10)}$.

No âmbito federal, o projeto é conduzido pelo Ministério da Educação (Secretaria de Educação Básica, Secretaria de Educação Continuada, Alfabetização e Diversidade), Ministério da Saúde (Programa Nacional de DST e AIDS, Área Técnica da Saúde do Adolescente e do Jovem e Departamento de Atenção Básica), UNESCO e UNICEF. Essas instituições constituem o Grupo Gestor Federal que está encarregado da elaboração de diretrizes, definição de estratégias, avaliação e monitoramento do projeto. De acordo com a demanda, o grupo organiza reuniões ampliadas com representantes de áreas específicas para subsidiar a construção da política. O grupo conta, ainda, com a colaboração de outras instituições, incluindo organizações da sociedade civil, que participam como consultoras ou colaboradoras do projeto ${ }^{(10)}$.

Vale ressaltar que o processo educativo ultrapassa a mera transmissão de informações. Ensinar não é 
transferir conhecimento, mas criar a possibilidade para a sua produção ou sua construção, quem ensina aprende ao ensinar e quem aprende ensina ao aprender. Assim, entende-se que o processo educativo envolve respeito à individualidade dos sujeitos e mútua colaboração. As atividades de caráter educativo têm o intuito de capacitar a população escolar para o desenvolvimento do autocuidado e assegurar a manutenção do estado de saúde ${ }^{(11)}$.

Durante muitos anos, programas de promoção de saúde em escolas foram desenvolvidos por meio de educação em saúde com abordagens convencionais, priorizando o domínio cognitivo e a memorização, com a transmissão de informações em um modelo de educação prescritivo e coercitivo. Entretanto, estas práticas, comprovadamente ,tiveram efeitos mínimos e de curto prazo por não provocarem mudanças efetivas em comportamentos ligados à saúde e qualidade de vida ${ }^{(3)}$.

A intersetorialidade proposta pelo Programa Saúde e Prevenção nas Escolas gera desafios em sua operacionalização já que insere a equipe de saúde da família no ambiente escolar. Diante dessa problemática o presente estudo teve por objetivos Investigar a percepção do professor sobre a inserção da equipe de saúde da família no ambiente escolar público; e Apontar as necessidades de cuidado aos adolescentes no ambiente escolar público prestados pela equipe de saúde da família.

\section{MÉTODO}

Esta pesquisa caracteriza-se como exploratório-descritiva de abordagem qualitativa. A pesquisa qualitativa é aquela em que o pesquisador tem como alvo a compreensão do comportamento e da experiência humana. O método exploratório-descritivo contempla o propósito do estudo, pois a pesquisa descritiva auxilia na observação, descrição e exploração de determinados aspectos de uma situação. A pesquisa exploratória busca descobrir as dimensões desse fenômeno, a maneira como ele se manifesta ${ }^{(12)}$.

Durante o estudo foram respeitados os princípios éticos de pesquisa envolvendo seres humanos, de acordo com a Resolução 196/96 do Conselho Nacional de Saúde $(\mathrm{CNS})^{(13)}$. Esta pesquisa foi aprovada pelo Comitê de Ética do Hospital Pequeno Príncipe, com registro no CEP n. 0764-09, e pela Secretaria Estadual de Educação do Estado do Paraná.

A pesquisa foi desenvolvida em 9 escolas estaduais no município de Curitiba, indicadas pela Secretaria Estadual de Educação, com professores das disciplinas de Educação Física e Ciências Biológicas e/ou Pedagogos.
Os critérios para inclusão dos participantes de pesquisa foram: atuar como professor na disciplina de Educação Física ou Ciências Biológicas ou ser Pedagogo da escola do estudo. As disciplinas de Ciências Biológicas e Educação Física foram adotadas neste estudo devido ao fato de serem as que abordam conteúdos com maior proximidade de temas de saúde.

A coleta de dados foi efetivada por meio de entrevistas semiestruturadas, gravadas e posteriormente transcritas. Utilizou-se também um questionário estruturado para obtenção das informações relativas a gênero, idade e tempo de atuação na função, tempo de atuação com adolescentes e grau de escolaridade (com vistas à pós-graduação). $\mathrm{O}$ período de coleta dos dados ocorreu entre março e maio de 2010. A identidade dos sujeitos do estudo foi preservada, de maneira que, para apresentação dos dados, seus nomes foram substituídos por nomes de pássaros silvestres brasileiros.

A análise dos dados de perfil, obtidos com o questionário, foi organizada com auxílio da estatística descritiva. A análise dos dados obtidos nas entrevistas foi realizada pela análise de conteúdo de $\operatorname{Bardin}^{(14)}$.

\section{RESULTADOS}

Participaram do estudo 12 profissionais sendo $60 \%$ na faixa etária entre 35 e 45 anos, $25 \%$ entre 25 e 35 anos e $15 \%$ acima de 55 anos. O gênero predominante foi o feminino com $60 \%$, em relação à função desempenhada, $40 \%$ eram professores de Biologia, $35 \%$ professores de Educação Física e 25\% Pedagogos. Quanto ao turno de trabalho, 15\% trabalhavam apenas no turno matutino, $25 \%$ trabalhavam nos três turnos e $60 \%$ dos profissionais trabalhavam dois turnos.

A partir da análise de conteúdo emergiram quatro categorias: 1- Interação entre profissionais de educação e profissionais de saúde; 2- Inserção de profissionais de saúde na escola; 3-Cuidados e informações aos alunos-adolescentes; 4- Desafios dos profissionais de educação ao trabalhar com alunos-adolescentes.

\section{DISCUSSÃO}

\section{Interação entre profissionais de saúde e profissionais de educação}

A cada discurso, os participantes sinalizaram carências no atendimento que a escola oferece aos alunos, explicitando a sobrecarga e a evidência de que o trabalho multidisciplinar é uma realidade possível e necessária. 
Essa interação é fundamental para transformar uma sociedade, tornando-a mais igualitária, com sujeitos proativos, que serão capazes de escrever sua própria história, tendo a saúde e a educação como alicerce nessa construção, de acordo com os depoimentos a seguir:

Olha! Sinceramente eu acho que sim! Mas não precisa ser uma coisa assim como o professor que tem uma carga horária, que precisa estar todos os dias, mas acho que deveria ser feito um trabalho junto com esses alunos como se fosse "palestra". (Azulão)

Sim, com certeza. O dia que está mais calmo eu atendo em média três alunos, mas geralmente atendo entre 10 e 11 alunos por dia. (Pardal)

Acredito que sim, por que acho que os dois se completam, no objetivo de educar a comunidade sobre a importância dos temas relacionados à saúde. (Patativa)

Essa necessidade é tão evidente que em 5 de dezembro de 2007 foi criado o Programa Saúde e Prevenção na Escola, instituído pelo Decreto Presidencial n. 6.286. Este tem como proposição de uma política intersetorial entre os Ministérios da Saúde e da Educação na perspectiva da atenção integral (prevenção, promoção e atenção) à saúde de crianças, adolescentes e jovens do ensino básico público e na educação de jovens e adultos, no âmbito das escolas e/ou das unidades básicas de saúde, realizadas pelas Equipes de Saúde da Família ${ }^{(10)}$.

A implementação do Programa prevê a articulação de diversas ações em saúde na escola que devem ocorrer de forma concomitante. Essas ações são apresentadas por componentes ou áreas temáticas agrupadas de acordo com a natureza das ações, como avaliação das condições de saúde dos estudantes, ações de promoção da saúde e prevenção de doenças e agravos, formação de profissionais e jovens para atuarem como multiplicadores, acompanhando a saúde dos estudantes e o próprio programa ${ }^{(10)}$.

\section{A percepção do professor sobre a inserção da Equipe de Saúde da Família trabalhando exclusivamente para a escola}

Os depoimentos a seguir ilustram a percepção dos participantes em relação à interação entre esses e a Equipe Saúde da Família:

Acho muito importante a presença de profissional de enfermagem dentro da escola. Ele pode tratar de assuntos de saúde que são de suma importância tanto para os alunos, como para os professores e pode também estender essas orientações à comunidade. (Canário Terra)

Quando é um caso de acidente normalmente eles chamam o professor de Educação Física por causa dos traumas, né? Os cuidados que tomar e a gente também não tem muito o que fazer, né? É pedir para que fique imóvel, põe um gelinho também para não inchar. É o básico. Você não tem como fazer nem uma avaliação, né? Por isso precisa de alguém aqui que entenda do assunto [...]. Posso citar, como exemplo, uma palestra que a enfermagem poderia fazer é sobre a alimentação, sobre o hábito de alimentação, falar sobre a importância dos horários das refeições. Muitos alunos chegam aqui passando mal por que não almoçam, vem direto sem comer, ou se entope de porcaria. (Pardal)

Muitos professores vêem a Equipe de Saúde da Família apenas como assistencial, e acreditam que sua atuação nas escolas irá auxiliá-los, pois precisam de alguém que tenha o conhecimento do atendimento ao aluno com alguma enfermidade ou trauma.

Porém, a função da Equipe de Saúde da Família vai muito além do trabalho curativo e imediatista. $\mathrm{O}$ enfermeiro é capacitado e deve atuar nas escolas focalizando a prevenção, orientando os alunos de como prevenir doenças e agravos, ter a percepção de que se a educação para a saúde for efetiva, suas complicações poderão ser amenizadas ou anuladas. Essa visão é bem importante e alguns professores já a possuem como podemos observar quando Azulão diz:

Veja só se vocêfaz aqui o trabalho preventivo, não chegar lá, isso gera menos gasto, investimento financeiro, você consegue fazer uma boa aplicação.

Outra preocupação dos professores é quanto à alimentação dos alunos, relatam que muitos não se alimentam direito e isso interfere no aprendizado desses indivíduos. Quando o assunto é alimentação há duas vertentes que devem ser avaliadas, uma é o hábito alimentar incorreto, ou seja, uma alimentação com baixo valor nutricional, rica em açúcar e gordura e, outra questão, sem dúvida a mais preocupante, consiste na falta de alimento, um problema social grave e realidade de muitos alunos que frequentam as escolas públicas. Quando se fala em adolescentes há ainda os transtornos alimentares, como obesidade, anorexia e bulimia. 
O Programa Saúde e Prevenção nas Escolas, entende como prioridade a questão da alimentação e propõe como meta às equipes de Atenção Básica e Saúde Bucal da Estratégia Saúde da Família, profissionais do Núcleo de Apoio à Saúde da Família e da área de Nutrição responsável pela alimentação escolar do município e estado, a realização de ações coletivas de orientação aos alunos. O objetivo é estimular a oferta de alimentos saudáveis e a escolha de opções adequadas, bem como a discussão de temas relacionados ao perfil nutricional e cultural de cada região ${ }^{(10)}$.

\section{Os cuidados que poderiam ser prestados aos adoles- centes pela equipe de saúde da família sob a ótica do professor}

Nesta categoria, observa-se possibilidades de atuação e necessidades, a partir dos depoimentos:

[...] inúmeros, né? Dá para fazer uma lista! Então, essa questão da puberdade, as principais mudanças e também tem outras doenças, né? Também, dependendo de onde a escola está inserida. Uma coisa que também acontece é a questão do piolho, principalmente com os menores. (Caboclinho)

Tem como orientadora sexual, eu gosto, eu trabalho muito com a área de sexualidade desde a quinta série. Mas às vezes é legal trazer um profissional de fora que seja capacitado pra vir falar também, das DST. Eu trabalhava num colégio que tinha curso de enfermagem, então as estagiárias iam fazer palestras. Por exemplo, Mal de Hansen, dramatização sobre AIDS. (Patativa)

Acho que estou na profissão errada, deveria ser psicóloga; se é menino quer falar sobre drogas, se é menina quer falar sexo, talvez por causa da disciplina. (Sabiá)

Os professores apontam inúmeras necessidades de cuidado que podem ser desenvolvidas pela equipe de saúde da família. Diversos assuntos relacionados à saúde podem ser trabalhados através de palestras, oficinas, dinâmicas, feira de saúde, debates, entre outros.

Essas atividades subsidiam os adolescentes a entenderem mais sobre o funcionamento dos seus corpos e o processo saúde/doença. Pode trabalhar ainda com fatores sociais que interferem no processo saúde/doença e medidas de prevenção de agravos dessas doenças como dicas de alimentação, autoestima, violência, álcool e drogas, entre outros. Além do trabalho individual ou em equipe, a enfermagem é capaz de agregar outros profissionais, trabalhar com equipe multiprofissional, a fim de melhorar a qualidade das informações aos adolescentes escolares.

O Programa Saúde e Prevenção nas Escolas percebe a necessidade da interação entre profissionais de saúde e educação e sugere que temas pertinentes a essa faixa etária sejam abordados e discutidos nas escolas, tais como: Promoção da atividade física, Educação para a saúde sexual e reprodutiva, Prevenção ao uso do álcool, tabaco e outras drogas, Promoção da Cultura de Paz e prevenção das violências e acidentes ${ }^{(10)}$.

Acredita-se que esses assuntos, ao serem trabalhados durante a vivência escolar, poderão embasar adolescentes, interferindo positivamente em suas decisões e isso poderá proporcionar melhorias nas suas condições de saúde e qualidade de vida.

\section{Os desafios dos profissionais de educação em traba- lhar temas relacionados à saúde com os Adolescentes}

As dificuldades enfrentadas pelos participantes podem ser ilustradas nos depoimentos:

Se a gente for ver nas escolas públicas a gente não tem muito assessoramento. A gente só tem a parte, vamos dizer assim, educacional, pedagógica. Nós não temos todos os professores não tem aquele conhecimento especifico. (Curió)

Agora tem a semana da dengue. O professor de Biologia que tem que dar, que tem que fazer, da gripe, sexualidade, drogas então, muita coisa, tudo para o professor de Biologia. (Sabiá)

Os conteúdos de Biologia são muito extensos, uma que a Biologia avança muito, você sempre tem que ir buscar a informação, e são poucas aulas na realidade, né? São pouquíssimas aulas mesmo, na grade muito pouco, nós estamos praticamente com duas aulas por semana, com essa infinidade de conteúdo, com a preparação pro vestibular e ainda com todas essas campanhas. Muita coisa direcionada ao professor de Ciências. Poderíamos dividir essa responsabilidade com alguém, né? (Curió)

Atualmente muitos estudos apontam para o espaço escolar público como ideal para desenvolvimento de atividades de promoção de saúde e prevenção de doenças. Nos últimos anos é notável o avanço da saúde pública, das medidas adotadas pelo Sistema Único de Saúde referente a Estratégia Saúde da Família envol- 
vendo a comunidade. Porém, nos setores que a saúde visou essa apropriação necessitam de adaptação desses equipamentos, mudanças em relação à estrutura física, organizacional e de pessoal. A Instituição Escolar também precisa de adaptações, os professores entendem a necessidade do trabalho multidisciplinar, porém apontam dificuldades existentes nessa evolução.

Quando a percepção da realidade está muito longe da realidade concreta, a ação estará longe de produzir os resultados esperados, por melhor que sejam as intenções. Repensar a prática educativa é o começo da mudança. É incoerente manter um discurso participativo e uma prática não correspondente ${ }^{(15)}$. É preciso considerar a educação como um processo de indagação e reflexão articulado às atividades básicas de saúde, o que significa a criação de espaços "nas escolas" a ser partilhado pela equipe de saúde da família, professores, alunos e seus familiares. Uma das formas para a busca de caminhos alternativos e para a transformação das situações que conduzam à melhor qualidade de vida é o levantamento das causas e consequências da saúde-doença e seus determinantes sociais, econômicos, políticos e culturais, num determinado momento histórico.

\section{CONSIDERAÇÕES FINAIS}

Vemos que um maior entrosamento entre profissionais da saúde da família e profissionais de educação é imprescindível para o sucesso desse trabalho. O ambiente escolar público expõe um rico campo de atuação para o desenvolvimento de ações de saúde, cabendo à equipe de saúde da família, além de suas competências habituais, atuar como articulador entre toda a equipe de saúde e os profissionais da educação, a fim de assegurar o desenvolvimento das ações previstas aos escolares e efetivar a intersetorialidade.

Os resultados desta pesquisa indicaram que as necessidades escolares incluem a equipe de saúde da família desempenhando um trabalho multidisciplinar dentro do ambiente escolar; a integração entre Escola e Unidade de Saúde será mandatória para desenvolver um trabalho sério de prevenção e promoção à saúde junto aos estudantes.

A equipe de saúde da família tem muitos enfoques de atuação junto a adolescentes nas escolas públicas e deve, para tanto, interagir com a equipe pedagógica de maneira a identificar metodologias que tornem interessante a temática abordada, com intuito de atrair esse público e transformar comportamentos. Os assuntos apontados pelos sujeitos do estudo: violência, drogadição, doenças sexualmente transmissíveis, higiene de modo geral, como corporal, bucal, da casa, dos alimentos; alimentação e autoestima poderão ser abordados por meio de palestras, oficinas, teatros, dança, música, jogos, entre outros. É preciso iniciativa e determinação para conquistar o espaço escolar e desenvolver um processo de educação em saúde participativo, que vise transformar adolescentes em cidadãos conscientes de seu papel social.

\section{REFERÊNCIAS}

1. Ferriane MGC. A inserção do enfermeiro na saúde escolar: análise crítica de uma experiência. Universidade de São Paulo: São Paulo; 1997.

2. Ministério da Educação (BR). Secretaria de Educação Fundamental. Relatório da Gestão Financeira do Exercício de 2001. Portaria Interministerial $n^{\circ} 766 /$ GM de 17 de Maio. [Internet] [acesso em 13 set 2009] Disponível: http://portal.mec.gov.br/seb/arquivos/pdf/ sef2001.pdf.

3. Moysés SJ, Moysés ST, Krempel MC. Avaliando o processo de construção de políticas públicas de promoção de saúde: a experiência de Curitiba. Ciênc. saúde colet. [Internet] 2004;9(3). [acesso em 17 set 2009]. Disponível: http://www.scielo.br/pdf/csc/v9n3/ a10v09n3.pdf.

4. Carvalho JN, Erdmann AL, Santana ME. A autonomia do cuidado exercido por adolescentes para um viver saudável: o olhar da enfermagem. Cogitare enferm. [Internet], 2011;16(2). [acesso em 15 ago 2011]. Disponível: http://ojs.c3sl.ufpr.br/ojs2/index.php/ cogitare/article/view/17545/14213.

5. Sanes MS, Arrieche TA, Cestari MEC. A educação no discurso de uma equipe de saúde da família. Cogitare enferm. [Internet] 2010;15(3). [acesso em 15 ago 2011]. Disponível: http://ojs.c3sl.ufpr.br/ojs2/index.php/ cogitare/article/view/18891/12200.

6. Krempel MC, Moysés ST. Ambientes saudáveis: uma estratégia de promoção de saúde. Projeto técnico, Secretaria Municipal de Saúde: Curitiba; 2002.

7. Acioli S. A prática educativa como expressãodo cuidado em Saúde Pública. Rev Bras Enferm. [Internet] 2008;61(1). [acesso em 22 ago 2009]. Disponível: http://www.scielo.br/scielo.php?pid=S003471672008000100019\&script=sci_arttext.

8. Guimarães CCPA; Velardi, M. Da educação sanitária à educação em saúde: o caminho para a escola promotora de saúde. [acesso em 10 out 2009] Disponível: 
http://www.paulofreire.org/twiki/pub/FPF2008/ TrabalhoClaudiaPacifico/Guimaraes_Claudia Cristina_Pacifico_Assis.doc.

9. Souza LM, Wegner W, Gorini MIPC. Health education: a strategy of care for the lay caregiver. Rev. Latino-Am. Enfermagem. [Internet] 2007;15(2). [acesso em 07 set 2009]. Disponível: http://www.scielo.br/pdf/rlae/v15n2/ v15n2a22.pdf.

10. Ministério da Saúde (BR). Manual de Diretrizes para Implementação do Projeto Saúde e Prevenção nas Escolas (SPE). Brasília; 2007.

11. Siston NA, Vargas LA. O enfermeiro na escola: práticas educativas na promoção da saúde de escolares. Enfermería global. [Internet] 2007; [acesso 12 set 2009]. Disponível: www.um.es/eglobal/article/ donwload/409/521.

12. Polit DF, Hungler BP. Fundamentos de pesquisa em enfermagem. $3^{\text {a }}$ ed. Porto Alegre: Artes Médicas; 1995.

13. Ministério da Saúde(BR). Conselho Nacional de Saúde. Diretrizes e Normas regulamentadoras de pesquisa envolvendo seres humanos. Resolução n. 196, de 10 de outubro de 1996. Brasília; 1996. [Internet] [acesso em 10 ago 2009]. Disponível: http://conselho.saude.gov.br/ resolucoes/reso_96.htm

14. Bardin L. Análise de conteúdo. Portugal: Edições 70, 2009.

15. Barreto TVS. Por uma educação amorosa e prazerosa. 2009. [acesso em 12 maio 2010]. Disponível: http:// taniama.blogspot.com/2009/04/por-uma-educacaoamorosa-e-praserosa.html 